\title{
Water Detection in Jet Fuel Using a Polymer Optical Fibre Bragg Grating
}

\author{
C. Zhang, X. Chen, D.J. Webb, G.-D. Peng ${ }^{1}$ \\ Photonics Research Group, Aston University, UK \\ ${ }^{1}$ University of New South Wales, Australia
}

\begin{abstract}
We present the results of initial experiments which show that a polymer optical fibre Bragg grating device has sufficient sensitivity to absorbed water to detect realistic levels of dispersed water in jet fuel.
\end{abstract}

Keywords: Jet fuel, water, humidity, polymer optical fibre, fibre Bragg grating, PMMA

\section{INTRODUCTION}

Water is a common impurity of jet fuel, and can exist in three forms: dissolved in the fuel, as a suspension and as a distinct layer at the bottom of the fuel tank. Water cannot practically be eliminated from fuel but must be kept to a minimum as large quantities can cause engine problems, particularly when frozen, and the interface between water and fuel acts as a breeding ground for biological contaminants. The quantities of dissolved or suspended water are quite small, ranging from about $10 \mathrm{ppm}$ to $150 \mathrm{ppm}$. This makes the measurement task difficult and there is currently a lack of a convenient, electrically passive system for water-in-fuel monitoring; instead the airlines rely on colorimetric spot tests or simply draining liquid from the bottom of fuel tanks. For all these reason, people have explored different ways to detect water in fuel ${ }^{1,2,3}$, however all these approaches have problems, e.g. they may not be electrically passive or they may be sensitive to the refractive index of the fuel. In this paper, we present a simple, direct and sensitive approach involving the use of a polymer optical fibre Bragg grating to detect water in fuel. The principle is that poly(methyl methacrylate) (PMMA) can absorb moisture from its surroundings (up to $2 \%$ at $23{ }^{\circ} \mathrm{C}$ ) , leading to both a swelling of the material and an increase in refractive index with a consequent increase in the Bragg wavelength of a grating inscribed in the material ${ }^{5}$.

\section{HUMIDITY SENSING}

The POF FBG used in this experiment was inscribed in a 200 micron diameter single mode, step index fibre, see Figure 1a. The fibre possessed a pure PMMA cladding with a core based on PMMA but containing dopants to raise the refractive index and enhance the photosensitivity. Inscription was carried out by scanning the $325 \mathrm{~nm}$ beam from a $\mathrm{HeCd}$ laser (Kimmon IK5652R-G) over about $6 \mathrm{~mm}$ of a phase mask with a period of 1.057 microns. The incident power was $30 \mathrm{~mW}$ and the total inscription time was 30 minutes. The reflection spectrum of the grating is shown in Figure $1 \mathrm{~b}$.

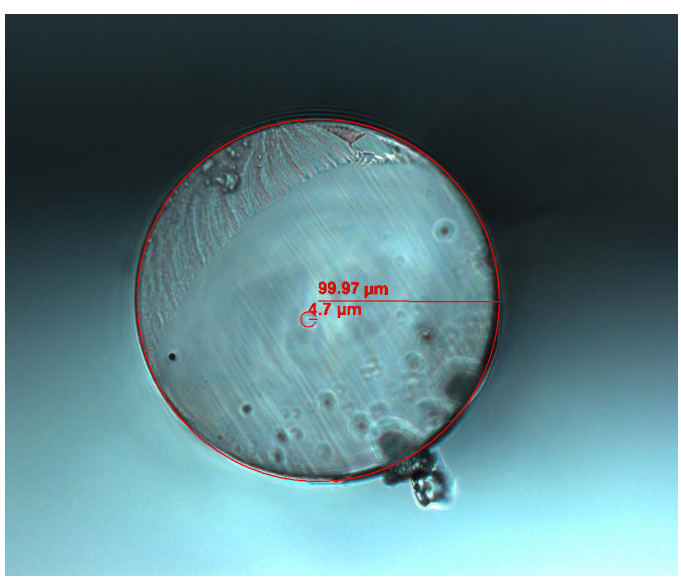

(a)

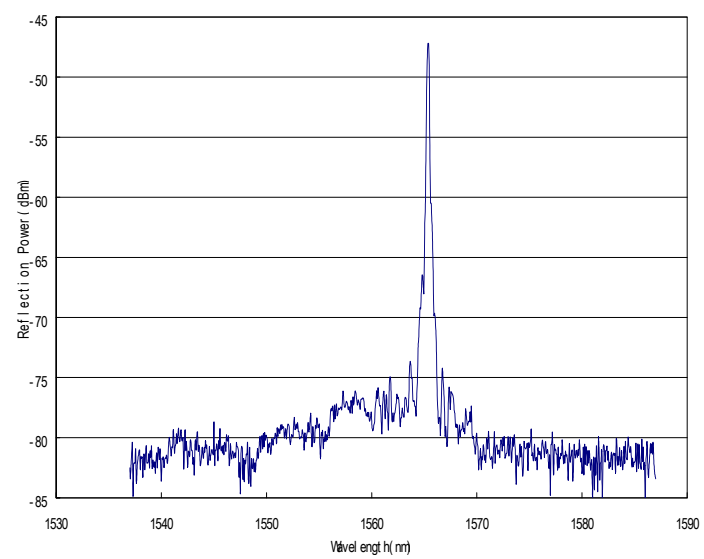

(b)

Figure 1: (a) optical microscope image of the cross-section of the SMPOF; (b) Reflection profile of fabricated FBG

20th International Conference on Optical Fibre Sensors, edited by Julian Jones, Brian Culshaw, Wolfgang Ecke, José Miguel López-Higuera, Reinhardt Willsch, Proc. of SPIE Vol. 7503, 750380 (c) 2009 SPIE $\cdot$ CCC code: $0277-786 X / 09 / \$ 18 \cdot$ doi: $10.1117 / 12.848696$ 
Because of the high loss of POF in the $1550 \mathrm{~nm}$ region, a short $(7 \mathrm{~cm})$ length of the fibre containing the grating was glued to a single mode silica fibre patch cord to form a device, which allowed us easily to monitor the Bragg wavelength change in reflection, see Figure 2.

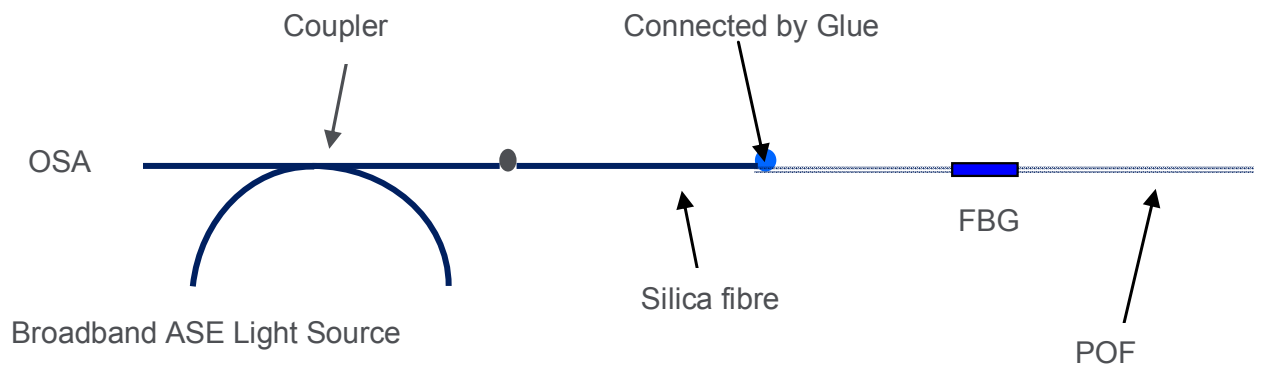

Figure 2: Sketch of the POF FBG device

To initially characterise the response of PMMA based POF FBG device to water, we placed the device inside an environmental chamber (SANYO Gallenkamp), allowing both temperature and humidity to be controlled. Initially the POF FBG was placed in the chamber with both the temperature and humidity held constant at $22^{\circ} \mathrm{C}$ and $45 \% \mathrm{RH}$ and the Bragg wavelength allowed to stabilise. With the temperature held constant, the humidity was then increased quickly to $52 \%$ and the Bragg wavelength monitored as a function of time, see figure $3 \mathrm{a}$. Approximately 30 minutes were required to reach equilibrium. With the temperature still held at $22^{\circ} \mathrm{C}$, the humidity was then changed in a series of steps from $45 \%$ to $90 \%$. At each step, 30 minutes was allowed for the humidity to stabilize. The results show that over this humidity range the device exhibits an apparently linear red-shift with increasing humidity with a sensitivity of $38.3 \mathrm{pm}$ per \% RH, see figure $3 b$.

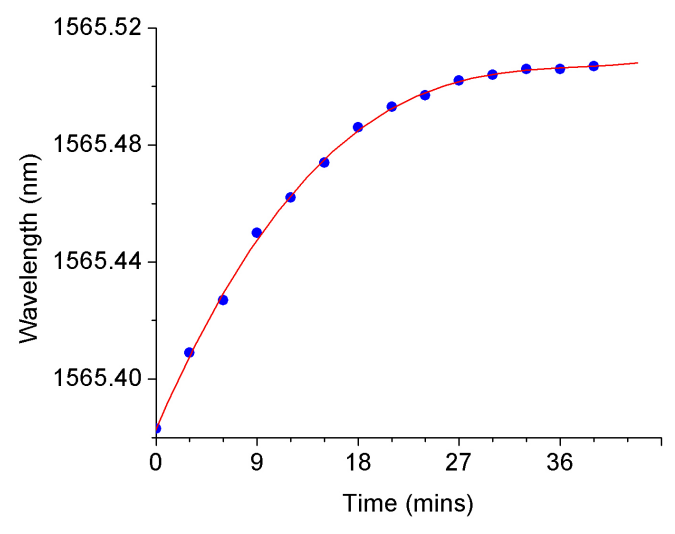

(a)

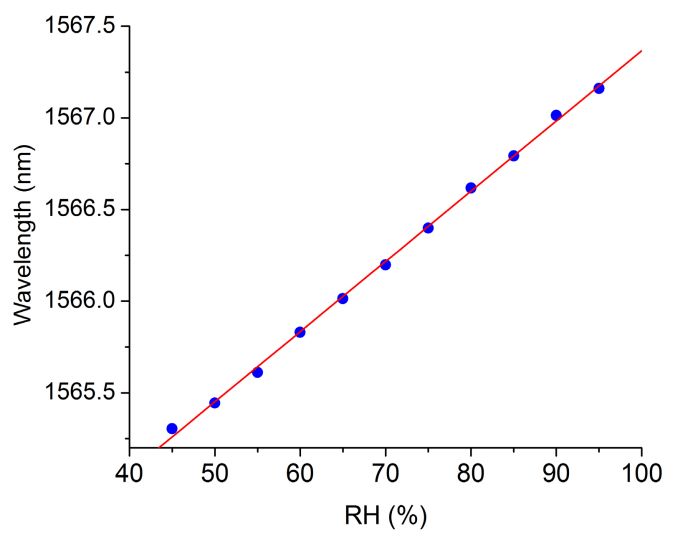

(b)

Figure 3: (a) Response of water absorption of PMMA based POF; (b) Humidity sensitivity of PMMA based fibre at 22 ${ }^{\circ} \mathrm{C}$.

While the sensor was in the environmental chamber, the thermal sensitivity was also characterised. With the humidity held constant at $45 \%$, the temperature was slowly increased in the range $18{ }^{\circ} \mathrm{C}$ to $36^{\circ} \mathrm{C}$ and the sensitivity determined to be $-43 \mathrm{pm} /{ }^{\circ} \mathrm{C}$. It may be seen that a temperature change of $1{ }^{\circ} \mathrm{C}$ and a humidity change of $1 \%$ produce very roughly the same shift in Bragg wavelength.

\section{WATER-IN-FUEL SENSING}

Based on the promising humidity sensing results we decided to investigate the potential of the POF FBG to detect small quantities of water in fuel. For a proof of principal experiment, three fuel samples were prepared in the following way. Dry jet fuel was prepared by taking $3.5 \mathrm{~g}$ of molecular sieve $3 \mathrm{~A}$ in a sample vial, which then had $10 \mathrm{ml}$ jet fuel added to it. 
The sample was then left for 24 hours for the sieve to remove the water. Wet fuel was prepared from a stock of dry fuel. $9.5 \mathrm{ml}$ of dry jet fuel were put into a sample vial and $0.5 \mathrm{ml}$ distilled water added ( $5 \%$ by volume). This sample vial was then shaken for 10minutes prior to running experiments to ensure that the water is mixed in with the fuel. Finally, a third fuel sample was obtained by taking fuel that had been exposed to ambient humidity for several days.

For this proof of principal experiment we had no means at hand to measure the dispersed water content of the three samples. However we know from other work that the dry fuel is likely to contain $15-20 \mathrm{ppm}$ water, the ambient fuel around 50ppm and the saturated (wet) fuel 120-150 ppm.

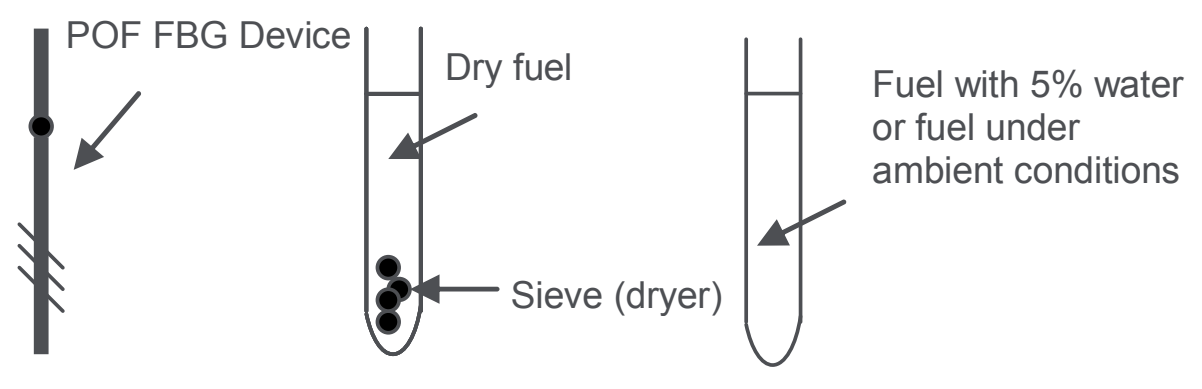

Figure 4: Sketch of the experiment setup

The dry fuel (with molecular sieve 3A, beads 8-12 mesh) and wet fuel (with 5\% distilled water) were separated into several test tubes sufficiently large $(7.5 \mathrm{~cm})$ to allow the POF and grating to be inserted, see Figure 4 . The sensor was then put into one dry fuel tube for an hour to make sure that the device achieved equilibrium. Then the device was put into wet fuel for 40 minutes to allow the maximum water absorption and red wavelength shift to be observed. After that, the device was taken out and put into dry fuel again and the Bragg wavelength was observed to shift back to approximately the original place. This procedure was repeated three times to confirm the repeatability of the results. The Bragg wavelength shift trend of the whole experiment is shown in Figure 5.

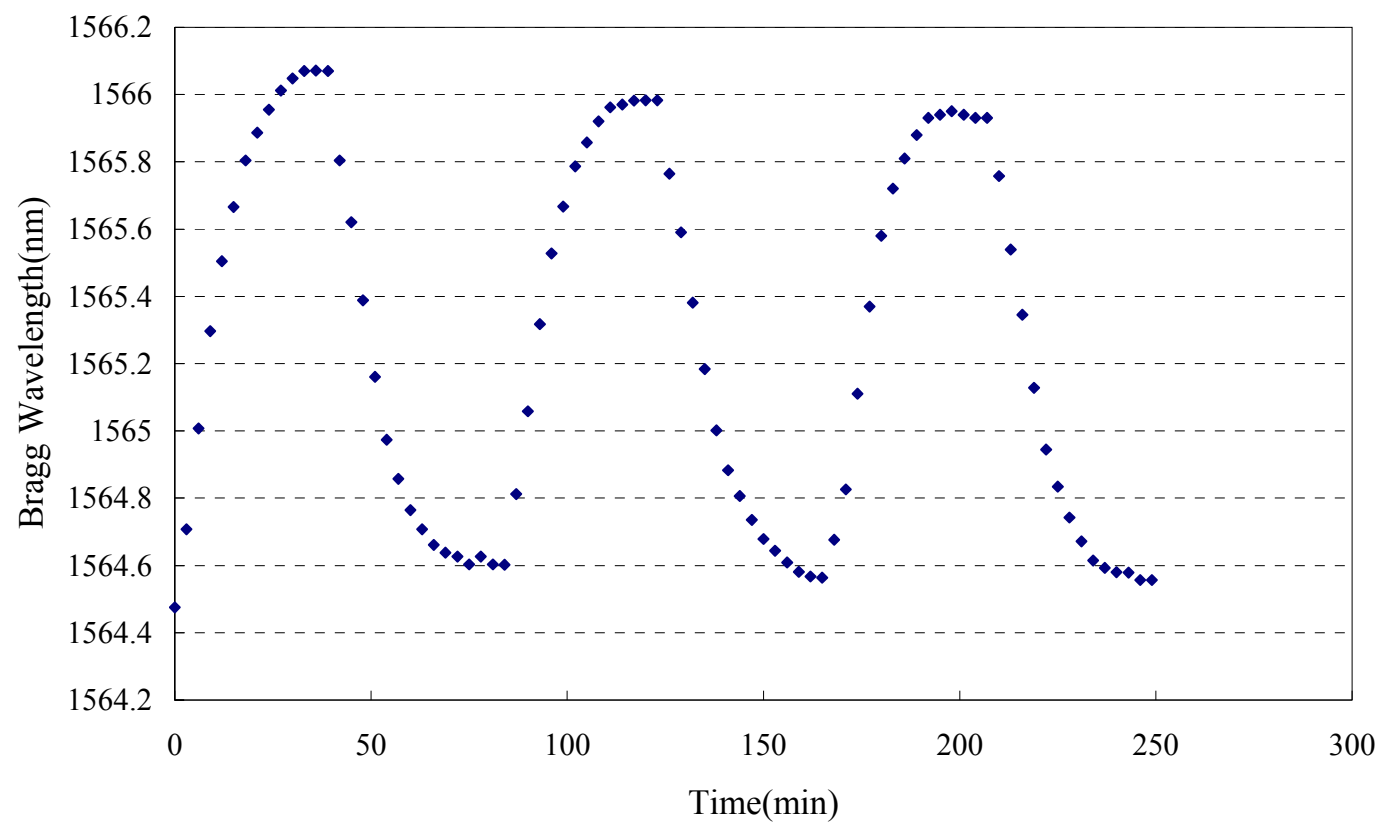

Figure 5: Bragg wavelength shift when the sensor was swapped between wet and dry fuel at room temperature.

As $5 \%$ water is quite a lot, a second experiment was carried out in a similar way but with the sensor being swapped between three fuel samples in the following order: dry, ambient, wet, ambient dry. The Bragg wavelength shift trend of this experiment is shown in Figure 6. 


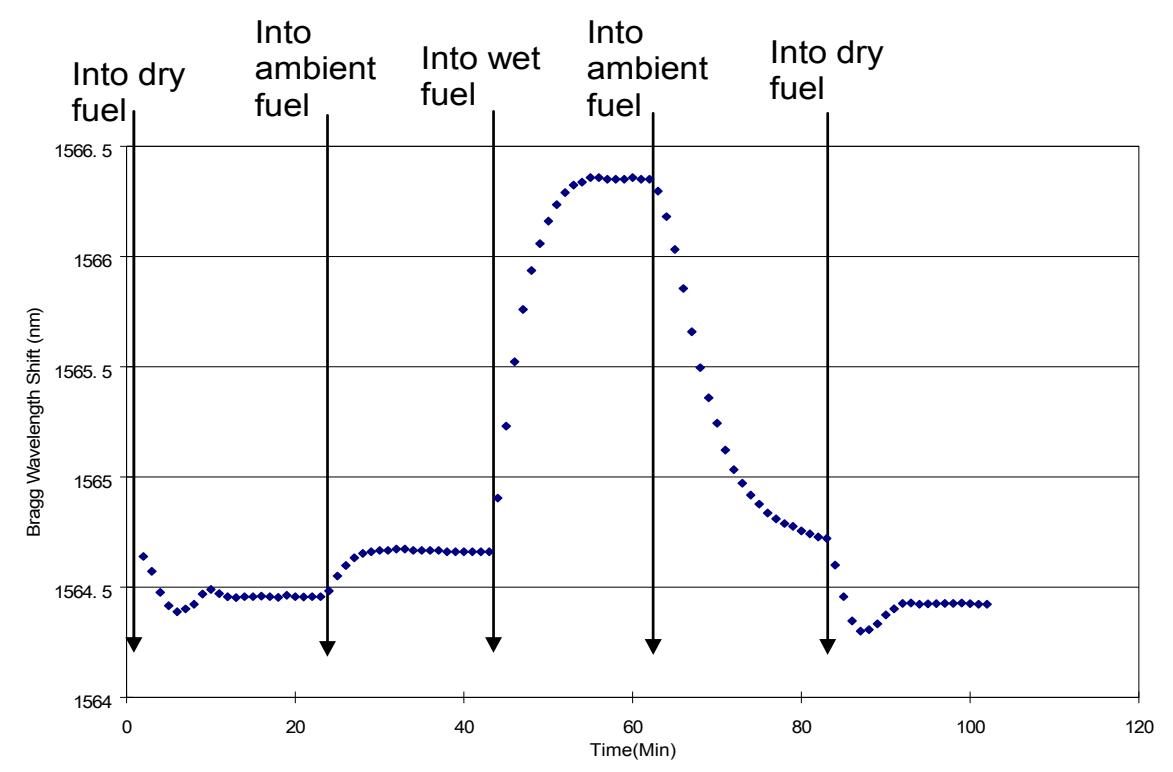

Figure 6: Bragg wavelength shift when the test was swapped between dry fuel, ambient fuel and wet fuel at room temperature

\section{DISCUSSION AND CONCLUSION}

The difference between dry and wet fuel is easily distinguishable in both experiments and even the change from dry to ambient samples is readily detected. In that regard the proof-of-concept experiments look to be very encouraging. There are however two points that need to be discussed. The first is the small but measurable differences observed in the Bragg wavelengths when the sensor returns to the same type of fuel. These differences show as a gradual decrease in the upper and lower Bragg wavelengths in figure 5 and a lack of precise match in the initial and final dry fuel readings in figure 6. We suspect that these differences are actually due to temperature changes of 1 or $2^{\circ} \mathrm{C}$ within the laboratory, which were not controlled for. The second issue is the response time of tens of minutes which would limit the real-time applicability of the technology. The fibre used was quite large, which will clearly have an adverse effect on the time taken for the water to diffuse into the core region. We expect that a smaller fibre diameter, possibly coupled with lapping the grating region of the fibre, will reduce the response time to a few minutes, which would open up the range of applications accessible.

\section{ACKNOWLEDGEMENT}

The authors acknowledge funding for this work from the UK Engineering and Physical Sciences Research Council and the EU FP7 Project "PHOSFOS".

\section{REFERENCE}

\section{WJ Lewis, WATER DETECTION DEVICE FOR FUEL LINE, US Patent, 3,787,650 (1974)}

2 Sean D. Pucketta and Gilbert E. Pacey, "Detection of water in jet fuel using layer-by-layer thin film coated long period grating sensor," Talanta, 78,1,300-304 (2009)

3 Kaida Khalid, Ionel Valeriu Grozescu, Lim Keng Tiong, Lee Teck Sim and Roslim Mohd, "Water detection in fuel tanks using the microwave reflection technique," Meas. Sci. Technol.,14,1905-1911 (2003)

4 Brandrup, J Polymer Handbook. Wiley 1999; Vols. 1\&2: V89

5 Harbach NG, Fiber bragg gratings in polymer optical fibers. Thèse EPFL, no 4021 (2008). Available at http://library.epfl.ch/theses/?nr=4021 